\title{
Anatomical study of intramuscular arterial patterns in rabbits
}

\author{
Daping Yang MD, Steven F Morris MD MSc FRCSC \\ Departments of Anatomy and Surgery, Dalhousie University, Halifax, Nova Scotia
}

D Yang, SF Morris. Anatomical study of intramuscular arterial patterns in rabbits. Can J Plast Surg 1998;6(4):183-189.

In order to identify intramuscular arterial patterns in the rabbit and select suitable muscles for experimental models of muscle transfer, 25 animals were injected with a lead oxide, gelatin and water mixture $(200 \mathrm{~mL} / \mathrm{kg})$. Twenty individual muscles from each rabbit were dissected. The length and size of the dominant vascular pedicle to each muscle were measured, and the location of the neurovascular hila was recorded. A total of 1000 muscles were radiographed and analyzed. The main patterns of the muscle arterial supply, based on the number of vascular territories, were described. Four main patterns of intramuscular vasculature were identified in these 20 muscles. This study provides detailed anatomical data of the intramuscular vasculature in the rabbit that allow an accurate anatomical delineation of rabbit muscle flap models and indicates that the rabbit muscle is an appropriate experimental model for various surgical research studies.

Key Words: Angiograph, Arterial pattern, Muscle flap, Skeletal muscle, Vasculature

\section{Étude anatomique des voies artérielles intramusculaires chez le lapin:}

RÉSUMÉ : Pour identifier les voies artérielles intramusculaires chez le lapin et choisir les muscles qui conviennent aux modèles expérimentaux de transfert musculaire, 25 animaux ont reçu par injection un mélange d'oxyde de plomb, de gélatine et d'eau (200 mL/kg). Vingt muscles individuels, provenant de chaque lapin, ont été disséqués. La longueur et la taille du pédicule vasculaire dominant pour chaque muscle ont été mesurées et la localisation de l'hile neurovasculaire a été notée. En tout, 1000 muscles ont été radiographiés et analysés. Les principales voies d'irrigation artérielle des muscles, selon le nombre de champs vasculaires, ont été décrits. Quatre principaux modes de vascularisation intramusculaire ont été identifiés dans ces 20 muscles. Cette étude fournit des données anatomiques détaillées sur la vascularisation intramusculaire chez le lapin, ce qui permet d'établir les limites anatomiques précises des modèles de lambeaux musculaires chez le lapin et indique que le muscle du lapin est un modèle expérimental approprié pour diverses études de recherche chirurgicale.

A variety of animal muscle or musculocutaneous flap models have been described and used in experimental flap research. In particular, the pig and dog models have been favoured, principally due to their large size and anatomy similar to that of humans. However, the pig and dog models may be expensive and difficult to use. Although the rabbit is relatively small, easy to work with, inexpensive to acquire and maintain, and suitable for long term study, few rabbit muscle models have been described. In preparation for fur-

This paper was presented at the 50th Annual Meeting of the Canadian Society of Plastic Surgeons, May 22 to 25, 1996, Halifax, Nova Scotia Correspondence and reprints: Dr Steven Morris, Room 4929, NHI, 1796 Summer Street, Queen Elizabeth II Health Sciences Centre, Halifax, Nova Scotia B3H 2A7. Telephone 902-473-7054, fax 902-473-8773,

e-mailsfmorris@is.dal.ca ther studies using the rabbit muscle model, we set out to document the available rabbit muscles suitable for experimental study.

\section{ANIMALS AND METHODS}

Twenty-five male New Zealand White rabbits (mean weight $3.1 \pm 0.1 \mathrm{~kg}$ ) were used for this study. The study protocol was approved by the Animal Care Committee of Dalhousie University. Each animal was sacrificed and, within 30 mins, injected with a lead oxide, gelatin and water mixture $(200 \mathrm{~mL} /$ $\mathrm{kg}$ ) through the carotid artery. Twenty of the largest and most superficial muscles of the rabbit were identified and dissected: the adductor longus, adductor magnus, biceps brachii, biceps femoris, extensor digitorum longus, gastrocnemius, gracilis, latissimus dorsi, pectoralis major, rectus abdominis, rectus femoris, serratus anterior, semimembrano- 


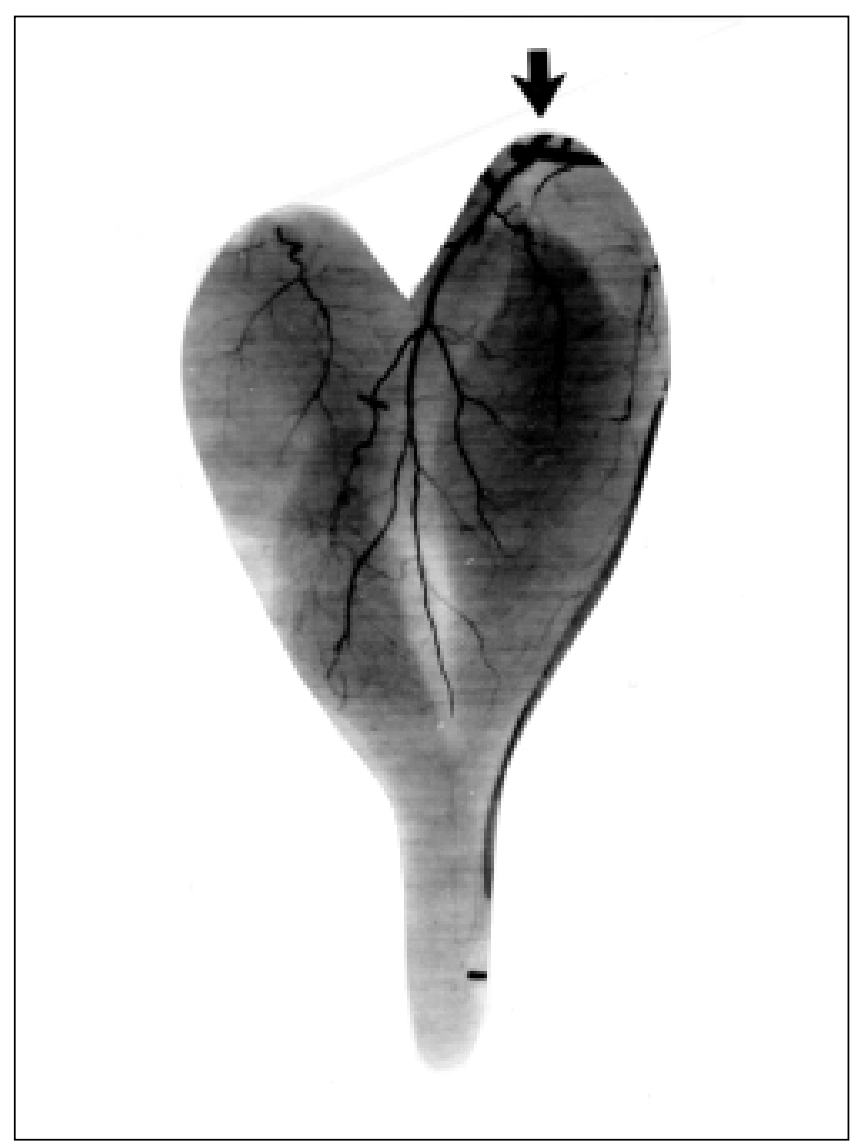

Figure 1) Angiogram of the rabbit gastrocnemius muscle showing the arterial trunk (arrow), which arises from the popliteal artery, running between the two heads of the muscle

sus, supraspinatus, tibialis anterior, triceps brachii, trapezius, vastus intermedius, vastus lateralis and vastus medialis. The length, size and origin of the arterial supply, and the entry point and origin of the nerve supply of each muscle were recorded. The muscles were then dissected out, radiographed and analyzed. The number of arterial territories in each muscle and the neurovascular relationship were described.

\section{RESULTS}

The vascular supply of each muscle is described, and several representative studies are presented. Four main patterns of vasculature, based on the number of arterial territories and their relative dominance within the muscle, are observed in this series of rabbit muscle studies. Muscles are classified as follows.

- Type A muscles have a single arterial territory from one major arterial pedicle supplying the muscle belly. Examples are the gastrocnemius, rectus femoris, serratus anterior and supraspinatus.

- Type B muscles contain two arterial territories from two different arterial pedicles, one of which is usually dominant. Examples are the rectus abdominis, gracilis, adductor longus and adductor magnus.

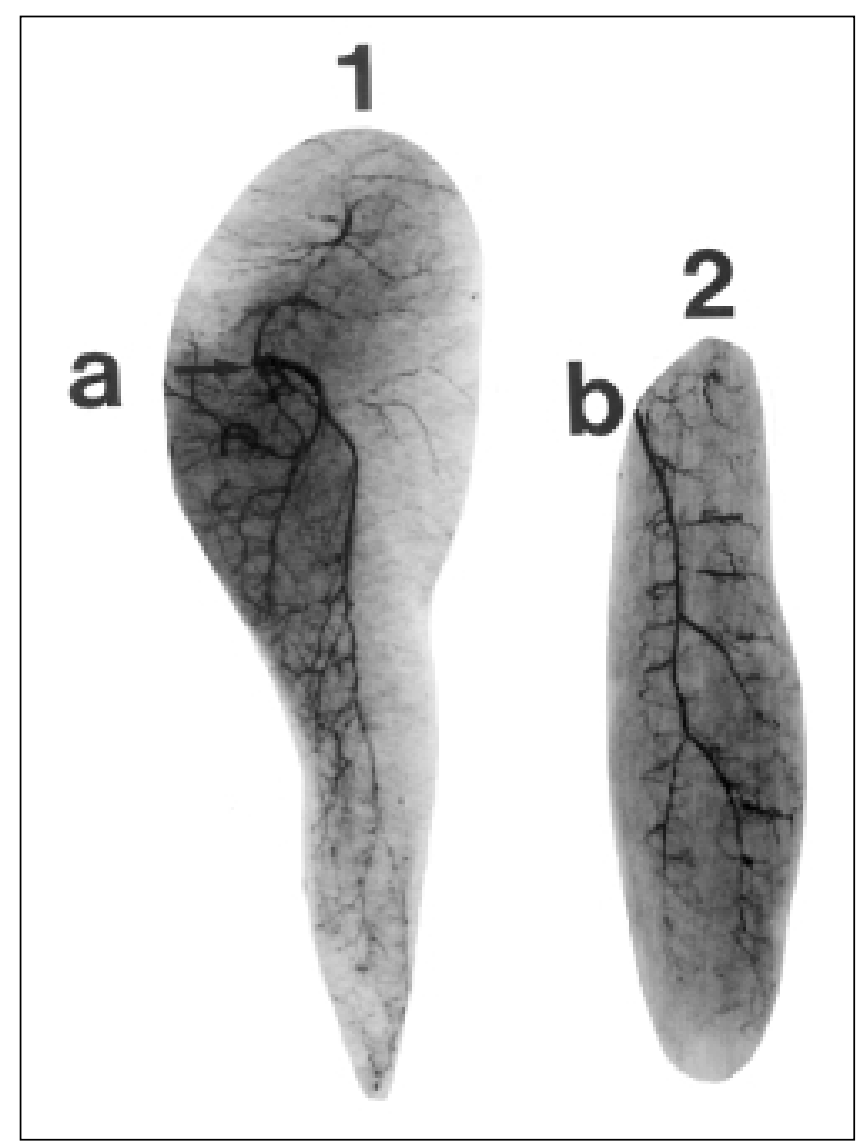

Figure 2) The rabbit rectus femoris consists of two distinct muscle bellies. The first part (1) receives a branch (a) from the ascending branch of the lateral circumflex femoral artery. The second part (2) receives a large muscular branch (b) from the lateral circumflex femoral artery

- Type $\mathbf{C}$ muscles consist of three territories from three pedicles: one is a dominant vascular pedicle and the others are inferior pedicles. Examples are the latissimus dorsi, trapezius, vastus lateralis and biceps femoris.

- Type D muscles consist of multiple territories from segmental vascular pedicles of similar size entering at multiple points along the belly of the muscle. Examples are the vastus medialis, vastus intermedius, biceps brachii and triceps brachii.

Ten muscles selected from different patterns as suitable models have the following characteristics: adequate size, superficial, straightforward dissection and constant neurovascular anatomy. These 10 muscles are the gastrocnemius, rectus femoris, rectus abdominis, gracilis, latissimus dorsi, biceps femoris, vastus lateralis, biceps brachii, triceps brachii and vastus medialis.

\section{Gastrocnemius (type A)}

The lateral head of the gastrocnemius is attached to the lateral condyles of the tibia and fibula, and the medial head is attached mainly to the medial condyle of the femur. The two heads have a common insertion on the calcaneus.

Most often the muscle is supplied by a single large vascu- 

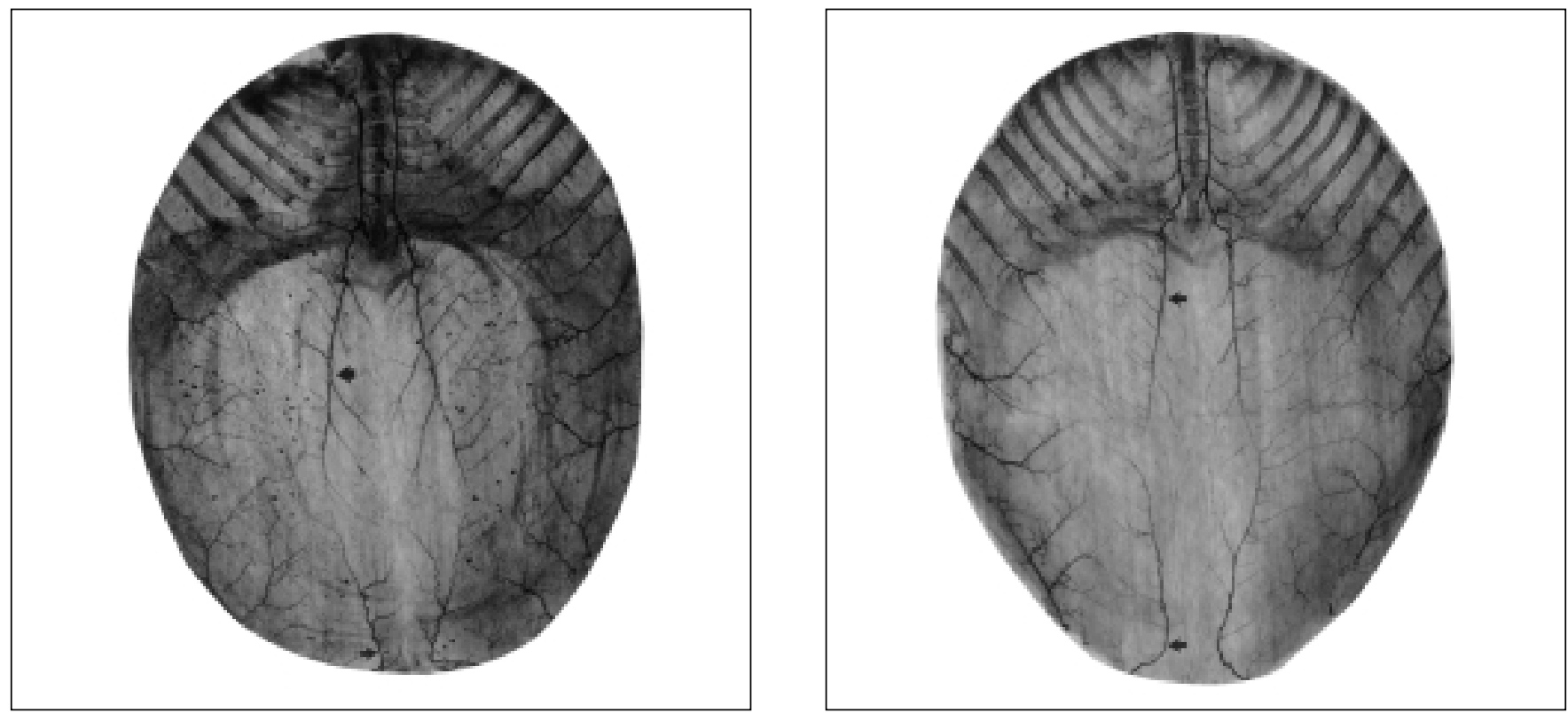

Figure 3) Two angiograms showing the overall vascular architecture of the anterior abdominal wall. The rectus abdominis is supplied by the cranial epigastric artery (upper arrows) and the deep caudal epigastric artery (lower arrows). Left The cranial epigastric artery supplies the upper two-thirds of the muscle. Right The cranial and caudal epigastric arteries are equal in size

lar trunk that runs close to the nerve of the muscle, forming the neurovascular pedicle. The arterial trunk arises from the popliteal artery proximal to the knee joint. It runs between the two heads of the gastrocnemius and divides into two branches, which give rise to the secondary branches to the lateral and medial heads. The mean length of the pedicle is $1.5 \mathrm{~cm}$, with an average diameter of $1 \mathrm{~mm}$. There is no anastomosis between these branches (Figure 1).

\section{Rectus femoris (type A)}

In the rabbit, the rectus femoris appears as two distinct muscles (1). The first part is superficial and has its origin on the iliac wing. The second part originates on the inferior anterior spine of the ilium. They have a common insertion on the tuberosity of the tibia.

The first part receives a branch from the ascending branch of the lateral circumflex femoral artery, which supplies both the tensor fasciae latae and the first part of the rectus femoris. The second part receives a large muscular branch from the lateral circumflex femoral artery. It reaches the muscle at its proximal attachment with a nerve branch from the femoral nerve. Its length and calibre are $0.8 \mathrm{~cm}$ and $1 \mathrm{~mm}$, respectively. Within the muscle this artery courses in the axial position and gives off branches, which then course in various directions (Figure 2).

\section{Rectus abdominis (type B)}

The rectus abdominis originates on the manubrium of the sternum and sternal costal cartilages, and inserts into the pelvic symphysis.

The rectus abdominis is supplied by the cranial epigastric artery and the deep caudal epigastric artery. The cranial epigastric artery, as the dominant artery, usually runs two-thirds of the length of the muscle in 41 of 50 cases (82\%) (Figure 3, left), whereas the cranial and caudal epigastric arteries were equal in size in nine of 50 cases (18\%) (Figure 3, right). The mean diameters of the cranial and caudal epigastric arteries are $1 \mathrm{~mm}$ and $0.8 \mathrm{~mm}$, respectively. The radiographs show the arrangement of the arteries within the muscle and the anastomoses between the cranial epigastric artery and the caudal epigastric artery. Choke anastomoses exist between the cranial and caudal epigastric arteries in $90 \%$ of cases, and true anastomoses exist in 10\% (Figure 3).

\section{Gracilis (type B)}

The gracilis, a thin, sheet-like muscle covering three adductor muscles, originates along the pelvic symphysis and is inserted in the fascia of the proximomedial surface of the leg. In its superomedial section the muscle receives a branch from the femoral artery. This branch supplies the medial third of the muscle. In its superolateral deep surface the muscle receives a large muscular branch arising from the deep femoral artery. This branch emerges directly from the adductor magnus muscle with a nerve branch, and supplies the lateral two-thirds of the gracilis muscle and skin overlying the muscle. This major pedicle has a length of $0.5 \mathrm{~cm}$ and a calibre of $0.5 \mathrm{~mm}$. There are some choke anastomoses between these branches (Figure 4).

\section{Latissimus dorsi (type C)}

The latissimus dorsi originates in the lumbodorsal fascia and on the last four ribs and is inserted on the deltoid tuberosity.

The muscle receives its blood supply mainly from the thoracodorsal artery (Figure 5). The mean length of the pedicle is $1.5 \mathrm{~cm}$, and its calibre is $1 \mathrm{~mm}$. The neurovascular hilum is located $1.4 \mathrm{~cm}$ distal to the muscle insertion. Two 


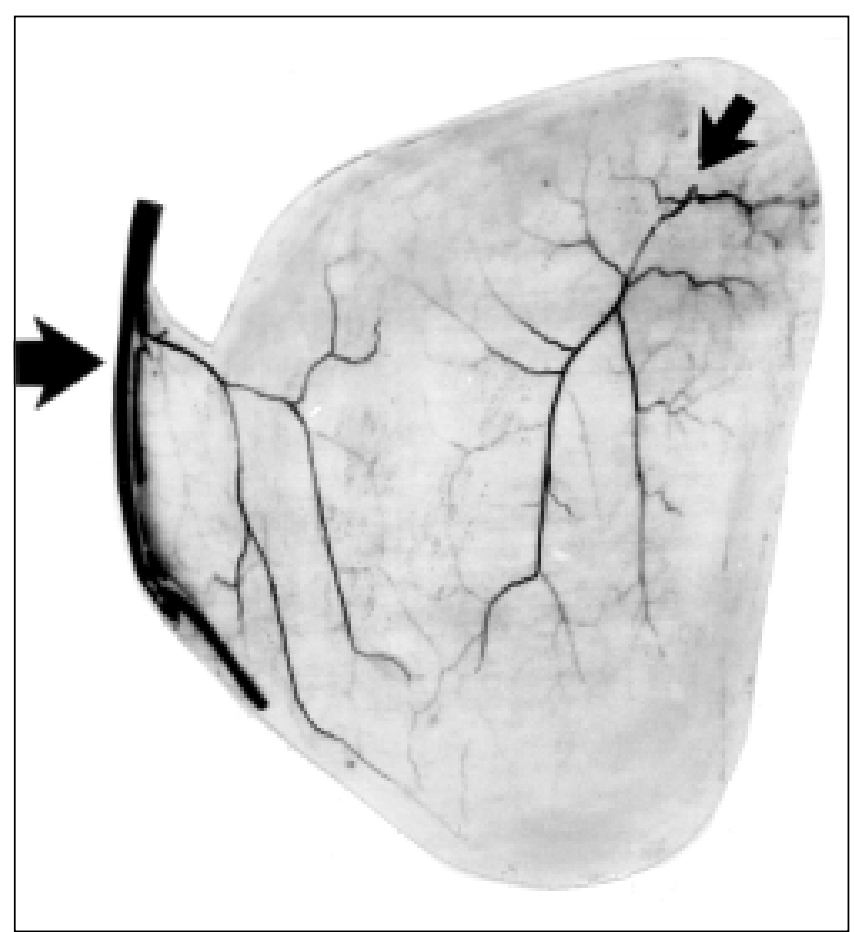

Figure 4) The sheet-like gracilis muscle in rabbits receives a branch from the femoral artery (left arrow), which supplies the medial third of the muscle, and a large muscular branch (right arrow) arising from the deep femoral artery, which supplies the lateral two-thirds of the gracilis muscle

large perforators of the posterior intercostal arteries supply the lower portion of the muscle. The arterial trunk runs parallel to the muscle fibres, and the secondary branches run perpendicular to the muscle fibres. There is an abundance of anastomoses between the thoracodorsal artery and the branches arising from the posterior intercostal arteries, and between the branches of the intercostal arteries themselves (Figure 5).

\section{Vastus lateralis (type $\mathbf{C}$ )}

The vastus lateralis is the largest of the quadriceps femoris group. It originates from the greater trochanter and has a common insertion on the tibia.

The vastus lateralis muscle receives its blood supply from three sources: the lateral circumflex femoral artery, the femoral artery and the popliteal artery. Each of these arteries sends a large branch to the muscle; two enter the muscle medially and one laterally. The superior medial artery originates from the lateral circumflex femoral artery. Within the muscle it usually runs medially and descends vertically on the anterior surface of the muscle. The other medial artery is of much larger calibre. It arises from a muscular branch of the femoral artery with a nerve branch from the femoral nerve and enters the deep surface of the muscle. The major neurovascular pedicle is located at the junction of the upper and middle thirds of the muscle. Its length and diameter are $1.5 \mathrm{~cm}$ and $1 \mathrm{~mm}$, respectively. Within the muscle, this artery takes an oblique inferolateral course, and the branches are transverse towards the lateral portion of the muscle. The lateral artery originates

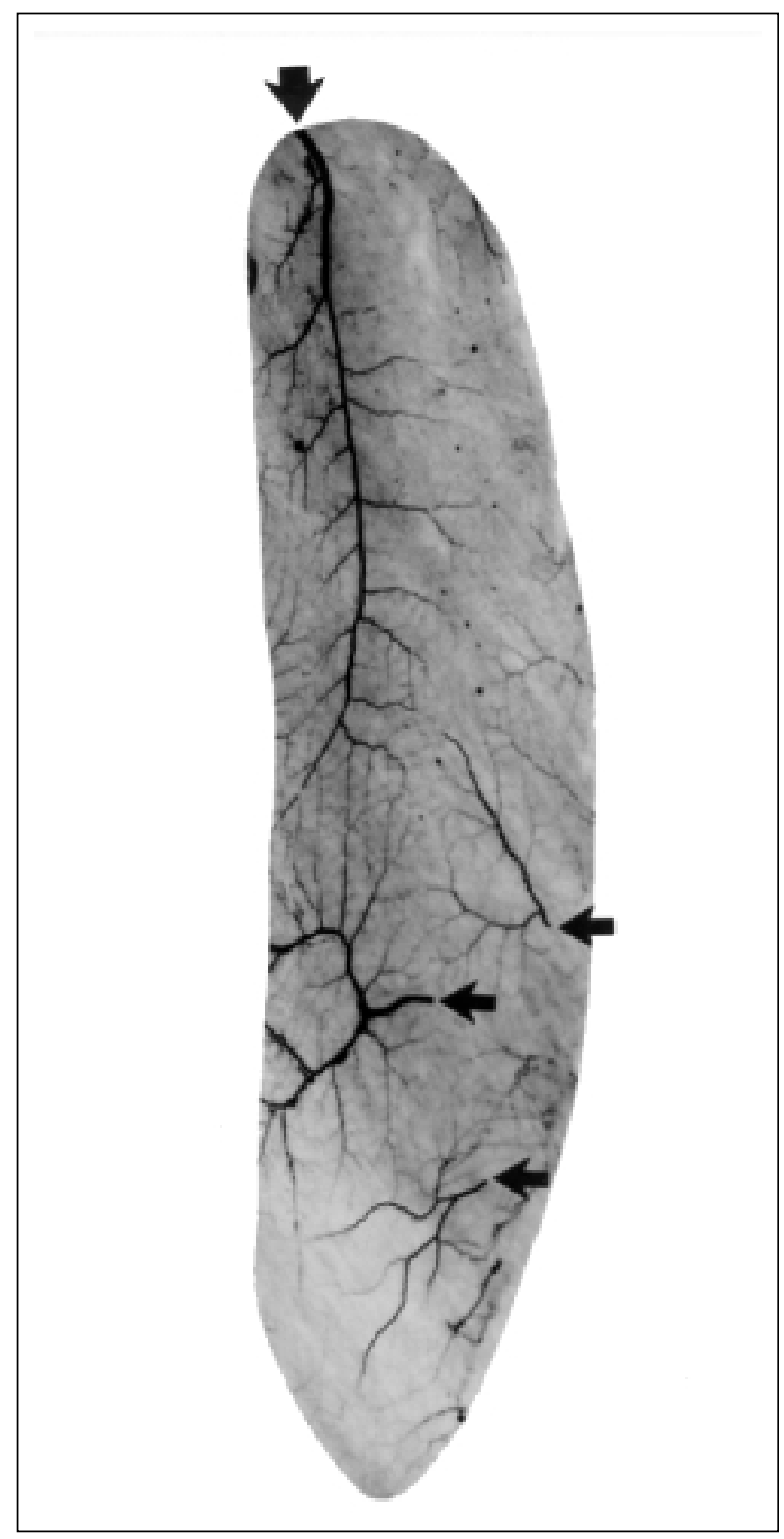

Figure 5) The latissimus dorsi receives its blood supply mainly from the thoracodorsal artery (upper arrow). Posterior intercostal arteries (lower arrows) supply the lower portion of the muscle

from the recurrent branch of the popliteal artery. It is of a smaller calibre and has a transverse course. Once it enters the inferior section of the muscle this artery divides into ascending and descending branches. Three arterial territories of variable size may be determined (Figure 6).

\section{Biceps femoris (type C)}

In the rabbit, the biceps femoris is a very large flat muscle that covers much of the lateral surface of the thigh. The two heads are quite separate (1). The first head has a broad origin over the sacral and caudal vertebrae, and a narrow insertion on the patella. The second head has a narrow origin on the 


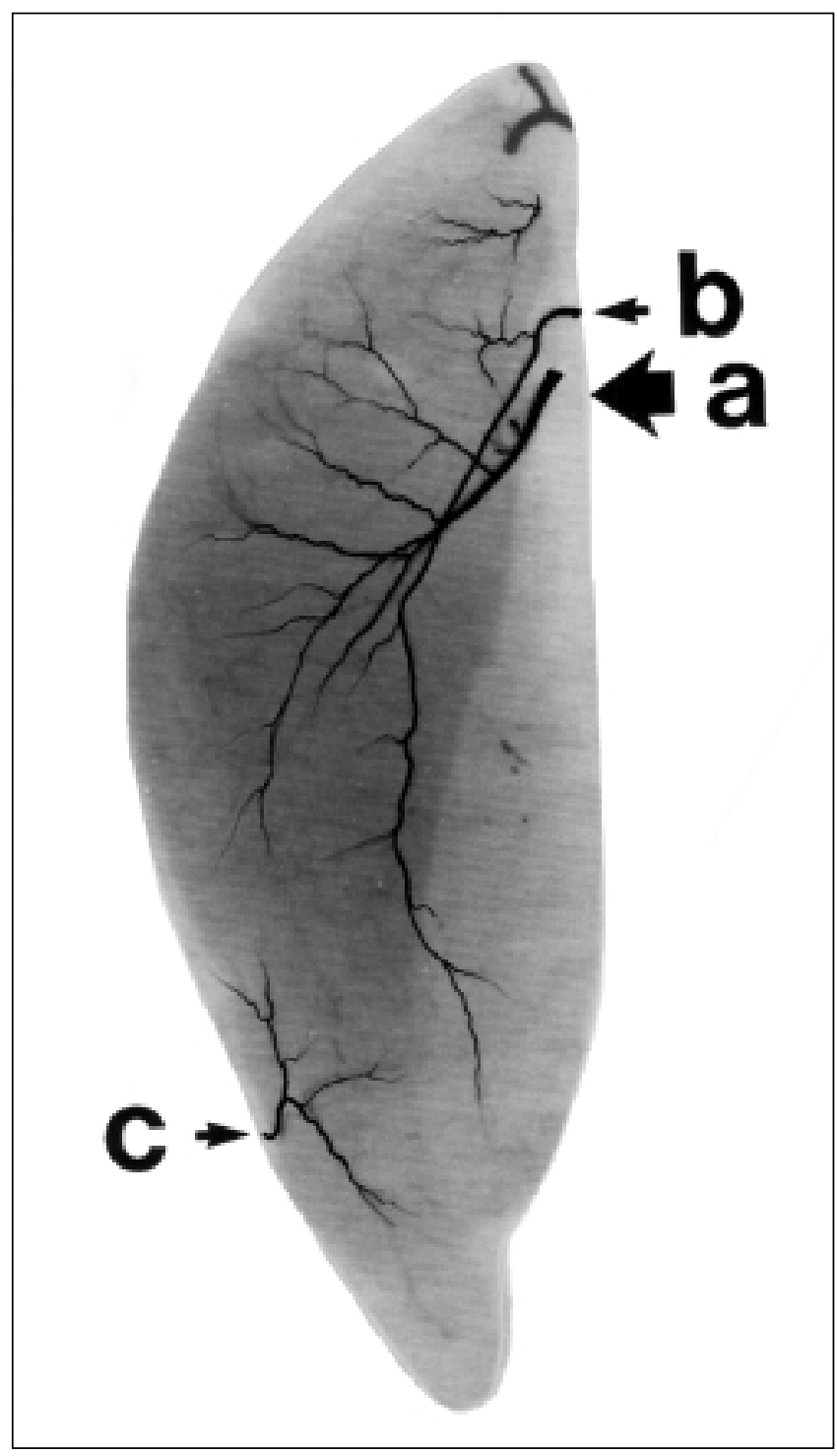

Figure 6) The vastus lateralis gets its blood supply from three sources: the lateral circumflex femoral artery $(a)$, the femoral artery $(b)$ and the popliteal artery $(c)$

ischial tuberosity and a broad insertion on the fascia of the lateral surface of the leg.

The muscle receives three branches. An artery arising from the popliteal artery is of large calibre. The artery is, on average, $1.8 \mathrm{~cm}$ in length, and its calibre is $1 \mathrm{~mm}$. The arterial trunk gives off two or three branches to the deep surface of the biceps femoris muscle at its distal third, where these branches enter both the first and the second head, and ascend to meet the superior artery. Within the first head of the biceps femoris, a superior arterial trunk with nerve from the sciatic artery and nerve has a vertical course, and its branches descend to the middle third of the muscle. There are numerous choke anastomoses between the descending branches of the sciatic artery and the ascending branches of the popliteal artery. The second head receives a muscular branch from the adductor magnus in its proximal portion. This branch runs obliquely downwards, deep to the second head of the muscle.

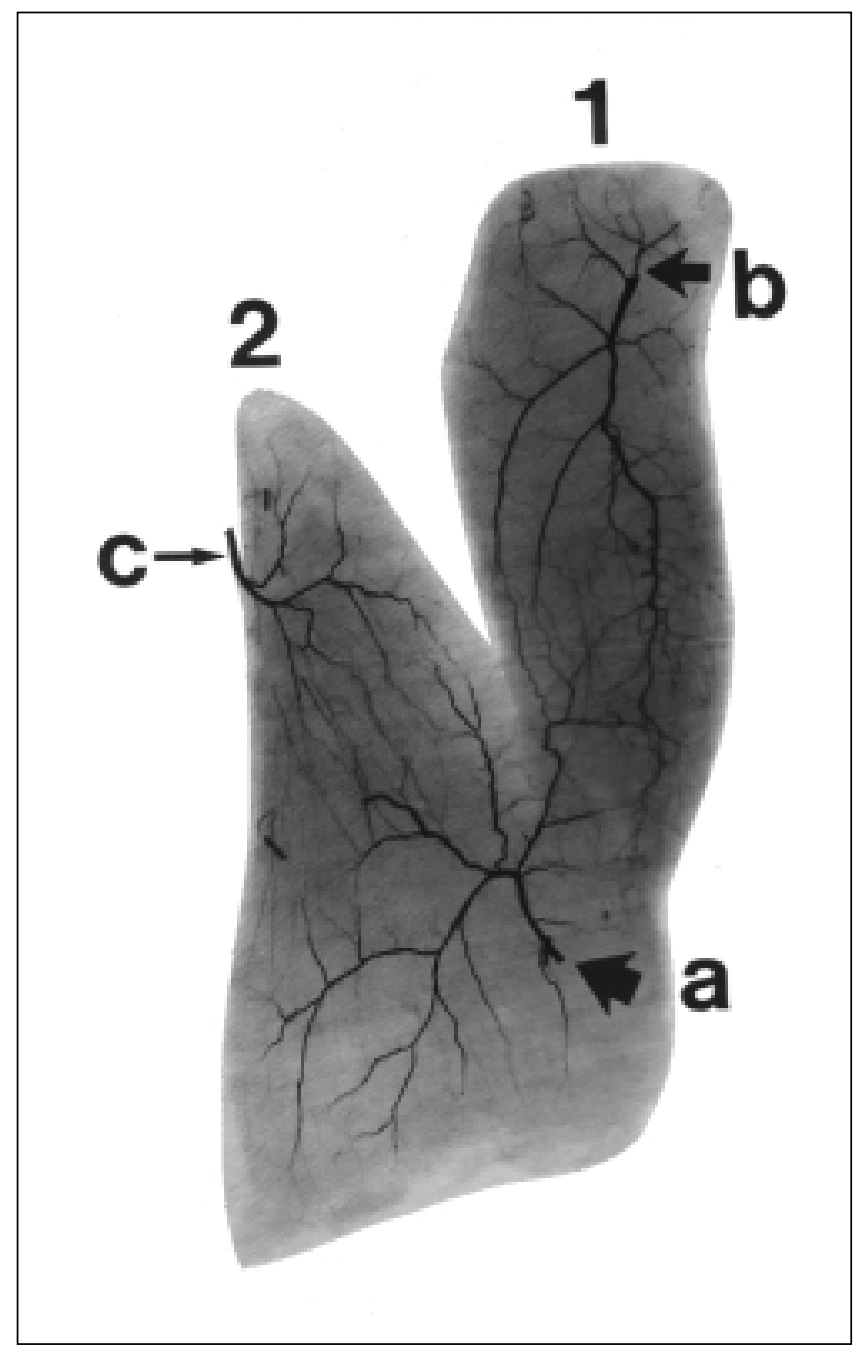

Figure 7) The biceps femoris is supplied by three arterial branches. A large arterial branch (a) arising from the popliteal artery gives off branches to both the first (1) and the second (2) head. In the first head, the superior arterial branch (b) from the sciatic artery enters the muscle at its superior third, while the second head receives a muscular branch (c) from the adductor magnus in its proximal section as well

There are some choke anastomoses between the descending branches of the superior artery and ascending branches of the popliteal artery. Two musculocutaneous perforators to the skin overlying the muscle are located in the middle third of the second head of the muscle. The perforators arise from ascending branches of the popliteal artery (Figure 7).

\section{Vastus medialis (type D)}

The origin of the vastus medialis is the medial surface of the neck of the femur, and the insertion is the tibia. The muscle receives multiple segmental arteries. The superior artery usually originates from the lateral circumflex femoris artery. This small branch enters the muscle at its proximal end and runs obliquely downward. Three other supplying arteries arise from the femoral artery. The average length is $0.5 \mathrm{~cm}$, with a diameter of $0.5 \mathrm{~mm}$. These arteries take a slightly oblique course and enter the medial half of the muscle at 


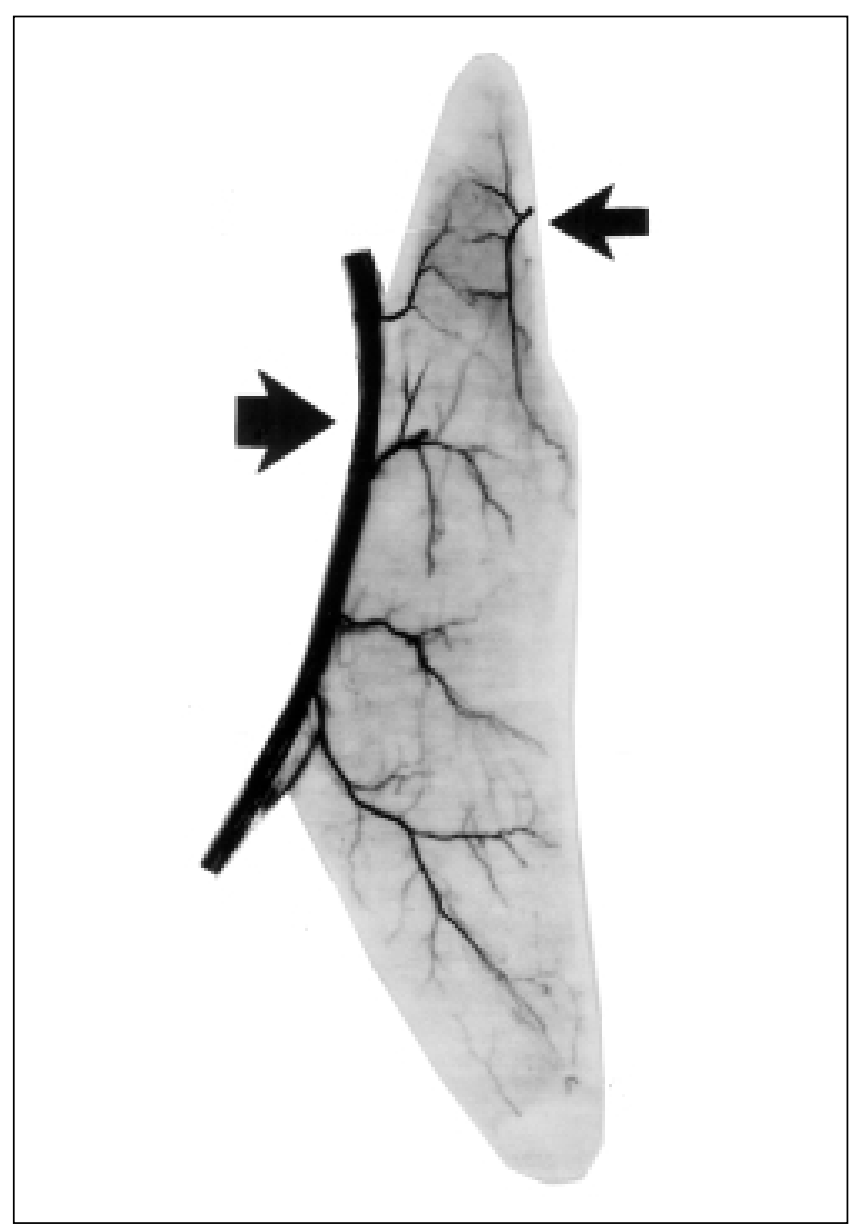

Figure 8) The vastus medialis receives multiple segmental arteries. The superior artery (right arrow) originates from the lateral circumflex femoral artery, and the other arteries originate from the femoral artery (left arrow)

superior, middle and inferior segments. Within the muscle, they divide early into ascending and descending branches and run parallel to the muscle fibres. A number of these branches anastomose with each other (Figure 8).

\section{Biceps brachii (type D)}

Biceps branchii has only one head in the rabbit (1). It originates on the cephalic edge of the glenoid cavity of the scapula and is inserted by another tendon on the medial surface of the radius and on the ventromedial surface of the ulna.

The muscle receives a segmental blood supply with three vascular pedicles from the brachial artery. These arterial pedicles are similar in size. The mean length of these pedicles is approximately $0.8 \mathrm{~cm}$, and the calibre is $0.5 \mathrm{~mm}$. The position of nerve entry is around the middle third of the muscle with one of the arterial pedicles, and the nerve pedicle is 1.2 $\mathrm{cm}$ long. The superior artery is short and transverse, while the middle and inferior arteries are long and oblique. All of the arteries enter the medial surface. Thereafter, these arteries give rise to fine branches running parallel to the muscle fibres. A number of these branches anastomose with each other (Figure 9).

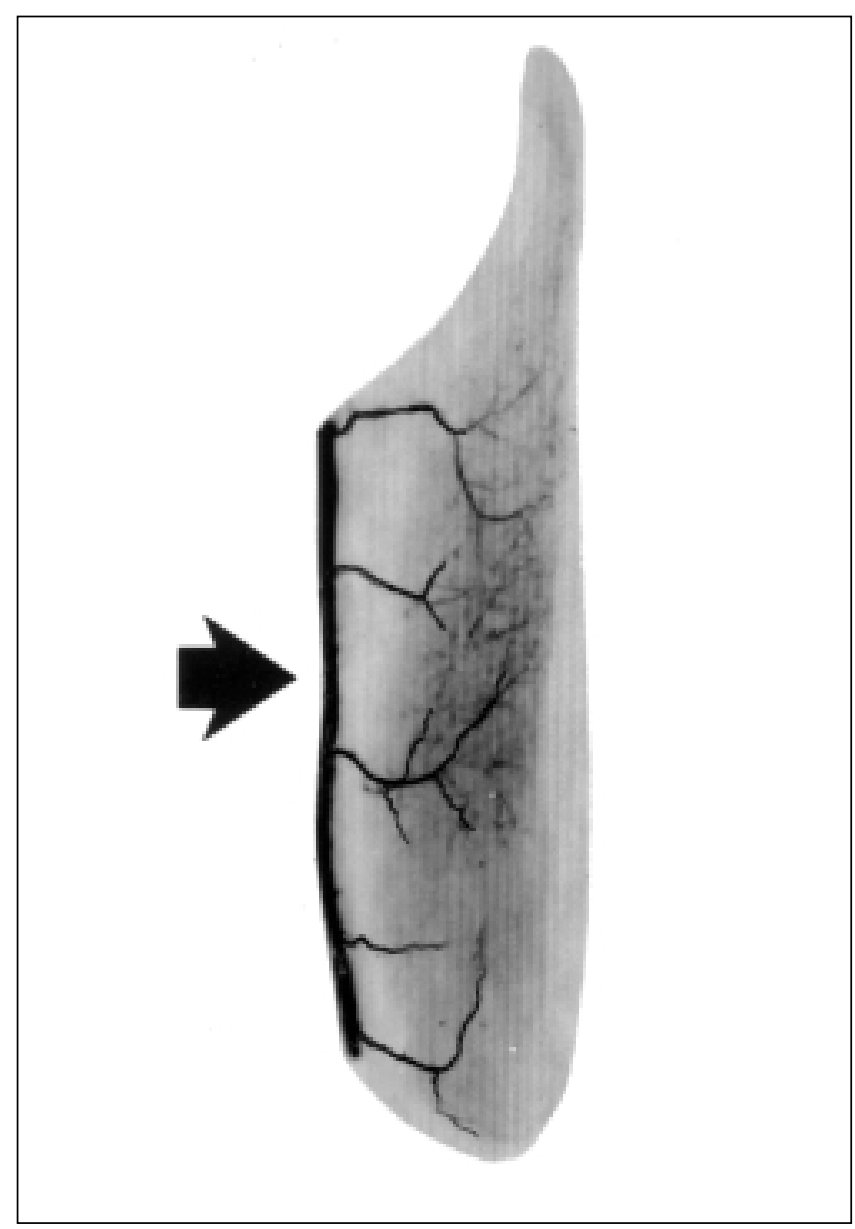

Figure 9) The biceps brachii has segmental vascular pedicles from the brachial artery (arrow)

\section{Triceps brachii (long head, type D)}

The long head of triceps brachii has its origin on the ventral part of the axillary border of the scapula and inserts on the olecranon. It is supplied anteriorly by three or four branches from the brachial artery, and posteriorly by one branch from the caudal circumflex humeral artery. The dominant branch from the brachial artery accompanied by one branch of radial nerve reaches the anterior surface of the long head. The mean length of the pedicle is $1 \mathrm{~cm}$, and the calibre is $0.6 \mathrm{~mm}$. The site of neurovascular hilum is $2.6 \mathrm{~cm}$ distal to the origin of the muscle. The radiograph shows some fine anastomoses between these branches (Figure 10).

\section{DISCUSSION}

Several rabbit muscles have been used as models for various experiments. For example, the rectus femoris muscle was chosen as a model for skeletal muscle reperfusion injury studies (2-4) and for vascularized muscle flap research (5-7). The rectus abdominis has been used as a pedicled muscle flap for the investigation of new arterial connections between the ischemic muscles and an independently perfused muscle pedicle flap (8), and as a myoperitoneal flap for the manage- 


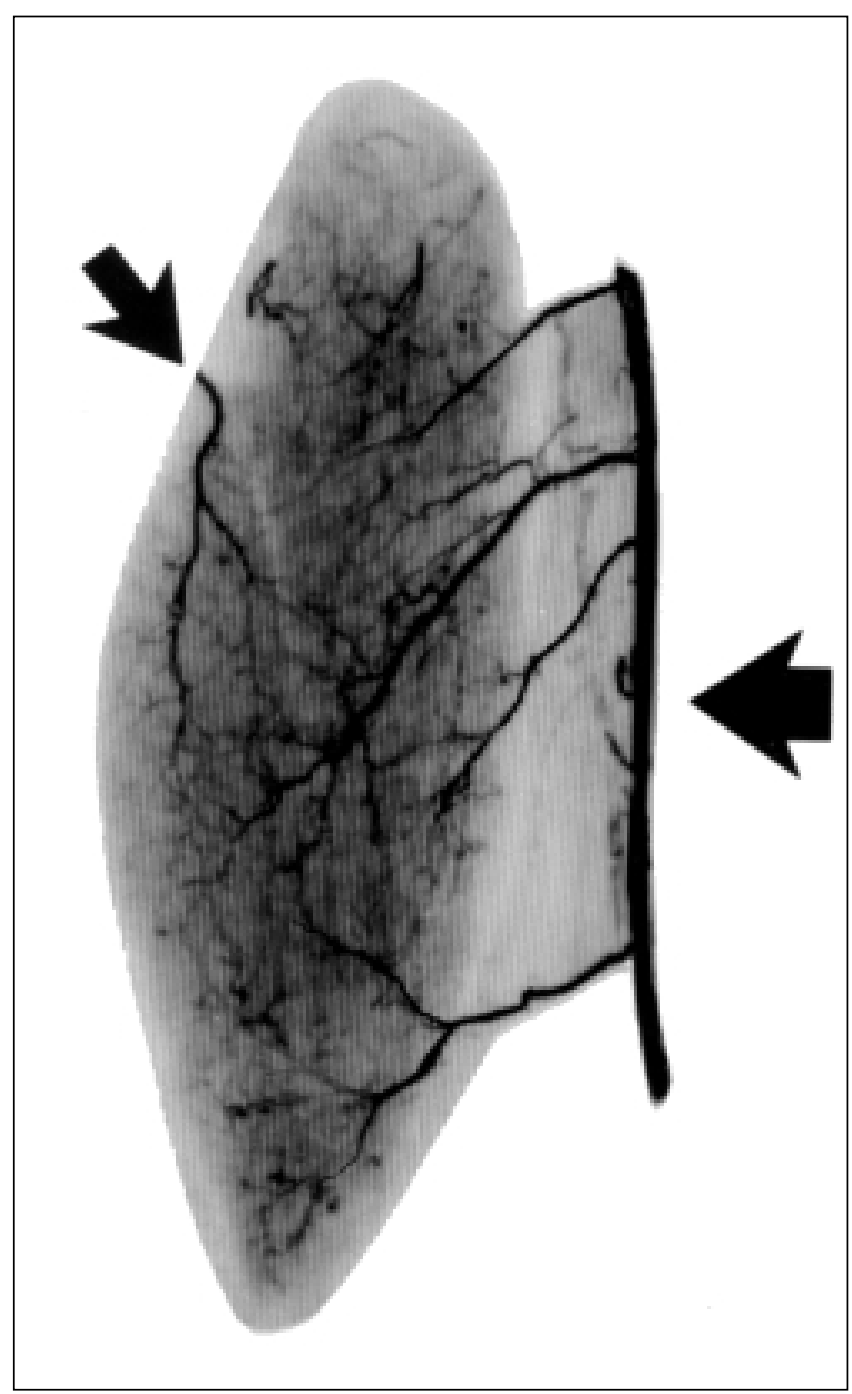

Figure 10) The triceps brachii (long head) is supplied anteriorly by three branches from the brachial artery (right arrow), and posteriorly by one branch (left arrow) from the caudal circumflex humeral artery

ment of large bladder defects (9). However, little is known of the intramuscular vasculature of the rabbit muscle. Although the angiograms of the latissimus dorsi, the gracilis and the rectus abdominis, selected from three rabbits, have been presented by Taylor and Minabe (10) in a study of comparative anatomy of a range of mammals and other vertebrates, the entire vascular anatomy of rabbit muscle appears to be absent from the literature.

The present study not only provides detailed anatomical data of the intramuscular vasculature of the rabbit, but also illustrates four fundamental intramuscular vascular patterns, which will aid in the design of muscle flaps for research purposes. Therefore, different muscle flaps can be selected on the basis of vascular patterns for various experiments in accordance with the requirements. For example, type A mus- cles with a single arterial territory are suitable for evaluating functional muscle transfer and skeletal muscle reperfusion injury. The muscle of type $\mathrm{C}$ is a suitable model for assessment of vascular delay in muscle flap and segmental split muscle flap. In a later investigation, we found that the latissimus dorsi and the biceps femoris are ideal muscle models for a surgical delay study. A detailed report on the use of the rabbit latissimus dorsi and biceps femoris muscles will follow in the near future.

\section{CONCLUSIONS}

This article provides a detailed anatomical study of the intramusclar vasculature in the rabbit and presents four fundamental intramuscular vascular patterns that will help researchers design muscle flaps. The different muscle models can be selected for various experiments in accordance with the requirements, such as pathophysiological studies of the muscular microcirculation, functional muscle transfer, study of skeletal muscle reperfusion injury, surgical delay in muscle flap and segmental split muscle flap.

ACKNOWLEDGEMENTS: The authors are grateful to Professor David Hopkins and Professor Robert Stone for their guidance and support for this project. We also wish to thank Ms Josephine Grant for her assistance in editing this paper.

\section{REFERENCES}

1. Craigie EH. A Laboratory Guide to the Anatomy of the Rabbit, 2nd edn. Toronto: University of Toronto Press, 1966:36-54.

2. Hickey MJ, Hurley JV, Angel MF, O'Brien BM. The response of the rabbit rectus femoris muscle to ischemia and reperfusion. J Surg Res 1992;53:369-77.

3. Breidahl AF, Hickey MJ, Stewart AG, Hayward PG, Morrison WA. Effects of low dose intra-arterial monoclonal antibodies to ICAM-1 and CD11/CD18 on local and systemic consequences of ischaemiareperfusion injury in skeletal muscle. Br J Plast Surg 1996;49:202-9.

4. Hoballah JJ, Mohan CR, Schipper PH, Chalmers RT, Corry DC, Corson JD. Rabbit rectus femoris muscle for ischemia-reperfusion studies: an improved model. J Surg Res 1996;66:21-4.

5. Guelinckx PJ, Faulkner JA, Essig DA. Neurovascular-anastomosed muscle grafts in rabbit: functional deficits result from tendon repair. Muscle Nerve 1988;11:745-51.

6. Burton HW, Stevenson TR, Dysko RC, Gallagher KP, Faulkner JA. Total and regional blood flows in vascularized skeletal muscle grafts in rabbits. Am J Physiol 1988;255:H1043-9.

7. Burton HW, Stevenson TR, White TP, Hartman J, Faulkner JA. Force deficit of vascularized skeletal muscle grafts in rabbits. J Appl Physiol 1989;66:675-9.

8. Pevec WC, Hendricks D, Rosenthal MS, Shestak KC, Steed DL, Webster MW. Revascularization of an ischemic limb by use of a muscle pedicle flap: A rabbit model. J Vasc Surg 1991;13:385-90.

9. Celayir S, Kilic N, Dervisoglu S, Buyukunal C. Rectus abdominis muscle flap (RAMF) technique for the management of large bladder defects: urodynamic findings in a rabbit model. Br J Urol 1996;78:294-7.

10. Taylor GI, Minabe T. The angiosomes of the mammals and other vertebrates. Plast Reconstr Surg 1992;89:181-215. 